Western University

Scholarship@Western

Biology Publications

Biology Department

$4-2014$

\title{
Localization and Chemical Speciation of Cadmium in the Roots of Barley and Lettuce
}

Mst. Fardausi Akhter

Christopher R. Omelon

Robert A. Gordon

Desmond Moser

Sheila Macfie

smacfie@uwo.ca

Follow this and additional works at: https://ir.lib.uwo.ca/biologypub

Part of the Biology Commons

Citation of this paper:

Akhter, Mst. Fardausi; Omelon, Christopher R.; Gordon, Robert A.; Moser, Desmond; and Macfie, Sheila, "Localization and Chemical Speciation of Cadmium in the Roots of Barley and Lettuce" (2014). Biology Publications. 43.

https://ir.lib.uwo.ca/biologypub/43 


\section{Localization and chemical speciation of cadmium in the roots of barley and lettuce}

Mst. Fardausi Akhter ${ }^{\mathrm{a}, 1}$, Christopher R. Omelon ${ }^{\mathrm{b}}$, Robert A. Gordon ${ }^{\mathrm{c}}$, Desmond Moser ${ }^{\mathrm{d}}$, Sheila M. Macfie ${ }^{\mathrm{a}, *}$

${ }^{\mathrm{a}}$ Department of Biology, Western University, London, ON, Canada, N6A 5B7, E-mail:

fardausi@gmail.com

${ }^{\mathrm{b}}$ Department of Geological Sciences, The University of Texas at Austin, Austin, TX, USA 78712-1722, E-mail: omelon@jsg.utexas.edu

${ }^{\mathrm{c} P a c i f i c ~ N o r t h w e s t ~ C o n s o r t i u m ~ S y n c h r o t r o n ~ R a d i a t i o n ~ F a c i l i t y, ~ A r g o n n e ~ N a t i o n a l ~}$

Laboratory, IL, USA 60439, E-mail: ragordon@alumni.sfu.ca

${ }^{\mathrm{d}}$ Department of Earth Sciences, Western University, London, ON, Canada, N6A 5B7, E-mail: desmond.moser@uwo.ca

* Corresponding author:

Sheila M. Macfie

Department of Biology, Western University

1151 Richmond St. N., London, ON, N6A 5B7, Canada

Tel: +15196612111

Fax: +1 5196613935

E-mail address: smacfie@uwo.ca

${ }^{1}$ Present address: Department of Veterinary Pathology, Western College of Veterinary Medicine, University of Saskatchewan, Saskatoon, SK, Canada S7N 5B4 
DOI: 10.1016/j.envexpbot.2013.12.005

(C) 2013. This manuscript version is made available under the CC-BY-NC-ND 4.0 license http://creativecommons.org/licenses/by-nc-nd/4.0/ 


\section{Abstract}

Plants have the potential to accumulate toxic amounts of cadmium (Cd), and understanding how and where Cd is stored in plants is important for ensuring food safety. Previous experiments have determined that a greater amount of $\mathrm{Cd}$ is translocated into the leaves of lettuce (Lactuca sativa) as compared to barley leaves (Hordeum vulgare). Preferential retention of $\mathrm{Cd}$ in root of barley would explain this difference. Hence, the purpose of this study was to determine the localization and coordination environment of Cd (i.e., the ligands to which Cd was bound) in the different root tissues of lettuce and barley using histochemical staining, electron microscopy and micro X-ray spectroscopy. Retention of Cd in barley roots could be explained by accumulation of $\mathrm{Cd}$ at the endodermis, comparatively higher amounts of Cd sequestered in the symplast of cortical cells and binding to xylem cell walls. Increased translocation of Cd to lettuce shoots seemed to be due to a less effective barrier at the endodermis and less sequestration of $\mathrm{Cd}$ in the cortex. Regardless of the tissue type, most of the $\mathrm{Cd}^{2+}$ was bound to $\mathrm{S}$ ligands in the roots of barley, possibly reflecting accumulation of Cd-phytochelatin and Cd-S molecules in the vacuoles. In lettuce roots, Cd was more evenly distributed among ligands containing $\mathrm{S}, \mathrm{O}$ and $\mathrm{NO}_{3}$ groups, which is indicative of proportionately more $\mathrm{Cd}$ binding to the cell walls, relative to barley. These results will be useful in uncovering the mechanisms of differential Cd-tolerance and sequestration in lettuce and barley.

Keywords: cadmium; electron spectroscopy; X-ray spectroscopy; chemical speciation; Hordeum vulgare; Lactuca sativa 


\section{Introduction}

The mechanisms of cadmium (Cd) uptake and tolerance in plants have been studied extensively (reviewed in Sanità di Toppi and Gabbrielli, 1999), but a clear understanding of what controls the translocation of $\mathrm{Cd}$ to aboveground tissues is lacking. One approach to better understanding the factors that control $\mathrm{Cd}$ accumulation and distribution is to determine where $\mathrm{Cd}$ is bound as it travels from the root surface to aboveground parts.

For some plants, the primary defense against $\mathrm{Cd}$ toxicity is exclusion of $\mathrm{Cd}^{2+}$ from active tissues and sequestration in non-active tissues. For example, Ouariti et al. (1997) showed that $98 \%$ of total Cd was retained in the roots of Phaseolus vulgaris with only $2 \%$ translocated to the shoot; presumably, much of the Cd in the root was in the apoplast or the vacuoles. When comparing Cd uptake and toxicity in Pisum sativum and Zea mays, Lozano-Rodriguez et al. (1997) found that the two species had equal concentrations of Cd in their roots and shoots but $P$. sativum exhibited more severe toxicity symptoms compared to Z. mays. The Cd in Z. mays was bound to the cell walls, which could explain increased Cd-tolerance. In plants such as Arabidopsis thaliana (Ager et al., 2002; 2003) and the Cd-hyperaccumulator Biscutella laevigata (Pielichowska and Wierzbicka, 2004), some of the Cd that is translocated is ultimately sequestered and rendered non-toxic in trichomes.

To understand better the distribution of Cd within a plant, it is insufficient to measure the concentrations of Cd in bulk tissues only (e.g., root, shoot, leaf, stem, etc.). Instead, the cellular and/or subcellular distributions of Cd in plant tissues could be determined using a variety of histochemical, imaging and physical fractionation methods. Histochemical 
methods include using Cd-specific dyes (Seregin and Ivanov, 1997; Vollenweider et al., 2006; Vieira da Cunha et al., 2008; Hu et al., 2009). However, it is possible that Cd is redistributed among and within cells during sample preparation, especially if tissue sections are immersed in an aqueous solution that could cause leaching of Cd. Images of the distribution of $\mathrm{Cd}$ in plants can also be obtained by using scanning electron microscopy (SEM) or transmission electron microscopy (TEM) along with energy dispersive X-ray spectroscopy (EDS, Solís-Domínguez et al., 2007; Hu et al., 2009) or energy dispersive X-ray (EDX) microanalysis (Rauser and Ackerley, 1987; Wójcik et al., 2005; Van Belleghem et al., 2007; Vazquez et al., 2007; Cocozza et al., 2008). Other imaging techniques include secondary ion mass spectrometry (SIMS, Migeon et al., 2011), micro-particle-induced X-ray emission ( $\mu$-PIXE, Ager et al., 2002; Vogel-Mikuš et al., 2008), and micro-autoradiography (Cosio et al., 2006). While the techniques listed above are able to detect Cd-specific signals in particular regions within a tissue, the low concentrations of $\mathrm{Cd}$ in the cells and the proximity of the emission spectra from Ca or K in the sample can make analysis difficult. In addition, unless tissue sections are fixed chemically prior to dehydration and embedding, Cd could be redistributed during sample preparation. Others have used subcellular fractionation to separate Cd-containing tissues and organelles (Weigel and Jäger, 1980; Wu et al., 2005; Wang et al., 2008); however, the centrifugation, filtering and washing steps are designed to rupture cells, which could release $\mathrm{Cd}$ and redistribute it among the fractions.

Synchrotron radiation-based analytical techniques have also been used to detect $\mathrm{Cd}$ at the cellular and subcellular levels (Isaure et al., 2006; Naftel et al., 2007; Fukuda et al., 2008; Harada et al., 2010; Terada et al., 2010). Micro-synchrotron X-ray fluorescence ( $\mu$-XRF) 
has a micron-scale beam spot size and highly sensitive detection systems that can provide spatially resolved maps of elements at the cellular scale. When added to micro X-ray absorption near-edge structure ( $\mu$-XANES) and micro X-ray absorption fine structure ( $\mu$ XAFS) spectroscopy, the system can also provide information on element-specific oxidation state(s) and coordination environment(s) of metals inside the cell. These techniques can be used to determine both where and to what $\mathrm{Cd}$ is bound within plant tissue.

Despite these robust methodologies, results from studies of the Cd distribution at the cellular and subcellular levels are not consistent. For example, Cd was not detected in the cell walls of $P$. vulgaris grown in $0.5 \mu \mathrm{M}$ Cd for $6 \mathrm{~d}$ (Vázquez et al., 1992) or Allium cepa grown in $10 \mathrm{mM} \mathrm{Cd}$ for $3 \mathrm{~d}$ (Liu and Kottke, 2004), whereas the cell wall was found to be a very important site for binding Cd in Hordeum vulgare grown in $5 \mu \mathrm{M} \mathrm{Cd}$ for $25 \mathrm{~d}$ (Wu et al., 2005) and Lupinus albus grown in $150 \mu \mathrm{M}$ Cd for 35 d (Vázquez et al., 2007). These differences could be due to differences among plant species or concentrations of $\mathrm{Cd}$ in the growth medium as well as different sample preparation techniques and different methods of detection.

In most of the studies mentioned above, the distribution of $\mathrm{Cd}$ was determined in hyperaccumulator plants, which can accumulate high concentrations of Cd (> $100 \mu \mathrm{g} / \mathrm{g}$ leaf dry weight, Bert et al., 2002) in their aboveground biomass without showing visible symptoms of toxicity. Those studies have provided useful information on qualitative imaging of cellular and subcellular Cd and, in a few cases, Cd speciation, and have also expanded our understanding of the mechanisms of Cd accumulation in hyperaccumulator 
plants. However, low metal-accumulating plants (such as agricultural crops) are expected to use different mechanisms to regulate their intracellular concentrations of Cd since lesser amounts of Cd tend to be taken up by these plants. Only a few studies have been conducted on the distribution of Cd in agricultural crops (Weigel and Jäger, 1980; Rauser and Ackerley, 1987; Seregin and Ivanov, 1997; Naftel et al., 2007; Vieira da Cunha et al., 2008; Terada et al., 2010), and none of these studies provided information on Cd speciation in the plants.

To address these knowledge gaps, we will apply multiple techniques including histochemical staining, SEM-WDS (wavelength dispersive spectroscopy), $\mu$-XRF and $\mu-$ XANES on samples taken from individual plants grown under identical experimental conditions, thereby providing a more consistent answer to the questions of where and in which chemical form Cd is localized. Lettuce (Lactuca sativa) and barley (Hordeum vulgare) were chosen because we previously found that approximately $80 \%$ of the total Cd was translocated to leaves of lettuce, whereas only $20 \%$ of the total Cd was translocated to barley leaves (Akhter and Macfie, 2012). This led to the hypothesis that barley and lettuce have different mechanism(s) to either store Cd in the root or translocate Cd to the leaves. Our objectives are (1) to determine the proportion of Cd bound within specific tissues of the root and (2) to use information about the coordination environment of Cd to predict the ligands to which $\mathrm{Cd}^{2+}$ is bound. 


\section{Methods and Materials}

\subsection{Germination and growth conditions}

Lettuce (L. sativa L. cv. Grand Rapids) and barley (H. vulgare L. cv. CDC McGwire, hulless 2-row feed barley) seeds were germinated in reverse osmosis (RO) water and grown in hydroponic culture for 28 days (d) under the same conditions as reported in Akhter et al. (2012) except, on day 7, individual seedlings were transplanted into $1.4 \mathrm{~L}$ jars filled with nutrient solution (adjusted to $\mathrm{pH} 6.0$ ) to which either 0 or $1.0 \mu \mathrm{M} \mathrm{CdCl}$ was added. Three replicate jars per experimental treatment were established.

In a preliminary experiment, we determined that concentrations of $\mathrm{Cd}$ in plants grown for $28 \mathrm{~d}$ with $1.0 \mu \mathrm{M} \mathrm{CdCl} 2$ were below the detection limits of electron and X-ray fluorescence spectroscopy. In an effort to increase the concentrations of $\mathrm{Cd}$ in the root tissues, we tried placing the plants in solutions containing $10,50,500,5000$ or $10000 \mu \mathrm{M}$ $\mathrm{CdCl}_{2}$ for 1 hour (h) prior to harvest. Concentrations of Cd were above the detection limits of electron spectroscopy only in plants from the two highest concentrations. We compared the distribution of $\mathrm{Cd}$ in roots grown in $1.0 \mu \mathrm{M} \mathrm{CdCl}_{2}$ for $28 \mathrm{~d}$ and harvested immediately to those that were soaked in 5 or $10 \mathrm{mM} \mathrm{CdCl}_{2}$ prior to harvest, using histological staining (see section 2.2.1), and found no visible differences. Therefore, on the $28^{\text {th }}$ day in hydroponic culture, the lettuce and barley plants from the $1.0 \mu \mathrm{M} \mathrm{CdCl}_{2}$ treatments were transferred into fresh nutrient solution ( $\mathrm{pH} \mathrm{6.0)}$ with $5.0 \mathrm{mM} \mathrm{CdCl}_{2}$ and 10.0 $\mathrm{mM} \mathrm{CdCl}_{2}$, respectively, for $1 \mathrm{~h}$. A comparatively higher concentration was selected for barley since it could accumulate higher amounts of Cd in the roots, compared to lettuce, without showing symptoms of Cd-stress (Akhter and Macfie, 2012). At harvest, 
fresh weights of roots and shoots were recorded, roots were rinsed in RO water and a $3.0 \mathrm{~g}$ subsample of root was immediately fixed in $2 \%(\mathrm{v} / \mathrm{v})$ glutaraldehyde (Electron Microscopy Sciences (EMS), Hatfield, PA, USA) and kept at room temperature overnight, to be used for microscopic analysis (section 2.2). The remainder of the root and shoot samples were oven-dried $\left(60^{\circ} \mathrm{C}\right)$ to constant weight and analyzed for total $\mathrm{Cd}$ content following the hot acid digestion and inductively coupled plasma optical emission spectroscopic (ICP-OES) methods described in Akhter and Macfie (2012).

2.2 Procedures for microscopic studies

\subsubsection{Light microscopy}

The localization of Cd in root tissues was studied using the histochemical method developed by Seregin and Ivanov (1997), which involves staining with dithizone, a reagent that produces an insoluble red salt, Cd-dithizonate, in the presence of Cd. Approximately one third ( $1 \mathrm{~g}$ ) of each root sample was removed from glutaraldehyde solution and cross sections were taken (hand sectioned) from the region a few mm above the root tip, where the cellular distribution of Cd was clearly visible. At the root tip, the concentration of Cd was very high, resulting in the entire tip region being stained red. The sections were placed on a glass slide with 2-3 drops of dithizone solution, covered by a cover slip and immediately examined under a light microscope.

\subsubsection{Dehydration and embedding}

The remaining root samples were embedded in epoxy resin following the method developed in the Geomicrobiology Laboratory, Department of Earth Sciences, Western 
University. Roots were taken out of glutaraldehyde solution, rinsed in RO water and cut into small pieces (1 cm in length). The sections were dehydrated in an ascending series of 25\%, 50\%, 75\%, 100\%, 100\%, 100\% acetone, with 15 min incubation at each step. After dehydration, the roots were gradually saturated with an epoxy resin mixture consisting of three components: embed 812, dodecenyl succinic anhydride (DDSA) and nadic methyl anhydride (NMA, each component from EMS, Hatfield, PA, USA) in a ratio of 20:9:10. The components were mixed using a vortex, and acetone was gradually replaced with epoxy resin by placing the sections in an ascending series of resin:acetone (1:1, 3:1, 9:1), with a $1 \mathrm{~h}$ incubation at each step or until the sample sunk to the bottom of the vial. Sections were left overnight in $100 \%$ epoxy resin to ensure complete impregnation of the root, followed by embedding in a fresh batch of epoxy resin consisting of embed 812, DDSA, NMA and 2, 4, 6-\{Tri(Dimethylaminoethyl) phenol\} (DMP-30, EMS, Hatfield, PA, USA) in a ratio of 20:9:12:0.72 before curing at $60^{\circ} \mathrm{C}$ for $48 \mathrm{~h}$.

2.2.3 Scanning electron microscopy with wavelength dispersive spectroscopy (SEMWDS)

One half of the embedded root samples were cut in cross section using a diamond saw to create a flat surface. The samples were then polished using a circular metallographic wet paper grinding wheel (60 grit/500 grit), starting with carborundum paper and ending with diamond paste. After polishing, the samples were coated with osmium tetroxide $\left(\mathrm{OsO}_{4}, 5\right.$ $\mathrm{nm}$ ) and mounted on aluminum stubs using carbon paint. Samples were analysed at high vacuum at an accelerating voltage of $15 \mathrm{kV}$ and a working distance of approximately $10 \mathrm{~mm}$ using a Hitachi SU6600 Field Emission Gun SEM at the Zircon and Accessory 
Phase Laboratory, Western University. Maps of the distribution of Cd were generated using wavelength dispersive spectroscopy (WDS; Goldstein et al., 1992). The spherical X-ray activation volume beneath the $1 \mathrm{~nm}$-diameter beam was approximately $1 \mu \mathrm{m}$ in radius. Each pixel in the map was approximately $2 \mu \mathrm{m}^{2}$. Relative quantification of Cd at both the cellular (epidermis, cortex, endodermis and vascular bundle) and subcellular (cell wall or “apoplast” and inside the cell or “symplast”) level was measured by point analysis of $\mathrm{Cd}^{2+}$ signals (counts per second) within each root cross-section. A total of three line scans were run across three different roots (experimental replicates). Within each scan, the signal at each sampling point was characterized as being from the epidermis, cortex, and endodermis, vascular tissue, apoplast or symplast. The average signal for each cell/compartment type was calculated and this value was used as the WDS signal for that cell/compartment type for that root.

\subsubsection{Micro X-ray fluorescence ( $\mu$-XRF) spectroscopy}

Hand-cut cross sections (approximately $200 \mu \mathrm{m}$ thick) were prepared from the remaining embedded roots using a razor blade. Similar to light microscopy, the sections were taken from the zone immediately above the root tip. Samples were mounted onto Rinzyl plastic slides (EMS, Hatfield, PA, USA) using double-sided carbon tape (Cedarlane Laboratories Limited, Hornby, ON, Canada) and analyzed at the 20ID beamline at the Advanced Photon Source. The experimental set-up followed that of Fukuda et al. (2008). The incident beam passed through a Si 111 monochromator on an insertion device (ID), detuned to $80 \%$ at $27260 \mathrm{~V}$ in order to excite the K-level emission lines of $\mathrm{Cd}^{2+}$. The high flux beam (approximately $2.5 \times 10^{10}$ photon/sec at $27260 \mathrm{~V}$ ) helped to generate 
measurement over a shorter period of time. The incident beam was focused to $4 \mu \mathrm{m} \times$ $6 \mu \mathrm{m}$ using a Kirkpatrick-Baez mirror assembly. Spatially resolved $\mu$-XRF analyses were conducted over $500 \mu \mathrm{m} \times 500 \mu \mathrm{m}$ regions of the samples, which were mounted 45 degrees to the incident beam. The fluorescence X-rays were measured using a 12-element Canberra $\mathrm{Ge}(\mathrm{Li})$ detector. The fluorescence X-ray intensity was normalized by the intensity of the incident X-ray beam to produce a two-dimensional Cd map.

Cadmium speciation was investigated with $\mu$-XANES (X-ray absorption near edge spectroscopy) at the points-of-interest identified from $\mu$-XRF Cd maps. $\mu$-XANES data collection was carried out from $150 \mathrm{eV}$ below the absorption edge energy to $\mathrm{K}$ values of $12 \AA^{-1}$. Each of the epidermis, cortex, endodermis and stele of the sectioned samples were scanned. Multiple scans were collected from each region of each species; however, only the first scan was included in the analysis since we observed additional features in the spectrum during the second scan, likely due to beam-induced damage to the sample. Cadmium standards (CdS, $\mathrm{CdSO}_{4}, \mathrm{CdCl}_{2}, \mathrm{CdNO}_{3}, \mathrm{CdO}$ and Cd-acetate) were spread onto Kapton ${ }^{\circledR}$ tape and XANES spectra were obtained at the 20BM beamline at the Advanced Photon Source. The incident beam was monochromatized on a bending magnet (BM), and detuned to $80 \%$ at $27000 \mathrm{eV}$ in an argon-filled ion chamber. The vertical slit was set to $0.5 \mathrm{~mm}, 50 \mathrm{~m}$ from the BM source. These XANES spectra were used to interpret spectra from experimental samples.

\subsection{Data analyses}

SigmaPlot (version 11.0) was used for statistical analyses and graphics. T-tests were used to compare Cd content, as measured by ICP-OES, in control plants versus Cd-treated 
plants. For estimates of Cd content in the various root tissues using SEM-WDS, one-way ANOVA was used to detect treatment effects and Tukey's test was used to determine significant differences among treatment means $(\mathrm{P}<0.05)$. The $\mu$-XANES spectra were analyzed using Athena version 0.8.056. The median spectra were corrected for background and normalized before linear combination fitting was performed. The goodness of fit was assessed using what we called the R-factor (the normalized sumsquares of the residuals between the model and the experimental data; Isuare et al. 2006).

\section{Results}

\subsection{Cd uptake}

The concentration of Cd was below the detection limit in the plants grown in $0 \mu \mathrm{M} \mathrm{Cd}$ except for roots of barley, in which the concentration was just above the detection limit (Table 1). After lettuce and barley roots were exposed to $5.0 \mathrm{mM} \mathrm{Cd}$ and $10.0 \mathrm{mM} \mathrm{Cd}$, respectively, for $1 \mathrm{~h}$ prior to harvest, the concentrations of $\mathrm{Cd}$ in the roots and shoots increased, with roots having 70 - to 230-fold higher concentrations than the shoots. The pattern was similar for the total amount of Cd (amount $=\mathrm{Cd}$ concentration $\times$ biomass); amounts of Cd increased in response to the higher Cd treatments and roots had 15-fold and 50-fold more Cd than the shoots in lettuce and barley, respectively. Regardless of differences in Cd concentrations, a higher proportion of the Cd taken up by the plant was translocated to the shoot in lettuce. At the end of the hour, lettuce plants were slightly wilted while barley remained turgid, indicating that barley is more tolerant of Cd. 


\subsection{Localization of $\mathrm{Cd}$ in the roots}

Representative images of lettuce (Fig. 1) and barley (Fig. 2) roots illustrate the patterns of Cd distribution determined by the various analytical techniques; images of roots stained with dithizone are in panels A-F, Cd distribution maps are in panels G (SEM-WDS) and $\mathrm{H}(\mu-\mathrm{XRF})$.

\subsubsection{Whole root and tissue-level distribution}

Roots from plants grown in the control treatment were not stained red by dithizone (Fig. $1 \mathrm{~A}$ and 2A); in every case, reddish coloured complexes were found only in Cd-treated tissues. Intense red staining, indicative of relatively high amounts of $\mathrm{Cd}$, was observed at the tips of roots hairs (Figs. 1B, 2B) and root tips (data not shown). Surface views of intact roots stained with dithizone showed distribution of $\mathrm{Cd}$ along the root length; the roots of barley (Fig. 2C) were redder than those of lettuce (Fig.1C).

\subsubsection{Cellular and subcellular distribution}

All the tissues of Cd-treated roots were stained by dithizone (Figs. 1D-F and 2D-F). However, the intensity of staining varied with the species and tissue types. In lettuce, the highest intensity of red stain was observed at the epidermis, with no differences in the intensity of Cd staining among the cortex, endodermis and stele (Fig. 1D). However, detailed imaging of the cortex showed a higher intensity of Cd staining in the apoplast (cell wall) compared to the symplast (inside the cell; Fig. 1E). The distribution of Cd in the stele was uniform (Fig. 1F). The higher amount of Cd associated with the epidermis was consistent with the Cd distribution maps generated by SEM-WDS (Fig. 1G) and $\mu$ - 
XRF (Fig. 1H) but differed from the semi-quantitative analysis based on WDS, which showed no differences in Cd signals among the four tissue types (Fig. 3A). However, similar to the imaging analyses, the semi-quantitative concentration of $\mathrm{Cd}$, as determined by SEM-WDS, was higher in the apoplast than in the symplast (Fig. 3B).

In barley, the darkest Cd-staining was observed in the endodermis and stele followed by the epidermis and cortex (Fig. 2D). Inside the cortex, Cd was detected with similar colour intensity in both the apoplast and symplast (Fig. 2E). Cadmium was detected in the endodermis and throughout the stele, with the highest stain intensity in the cell walls of the xylem and vascular parenchyma (Fig. 2F). This pattern was consistent with the Cddistribution maps generated by SEM-WDS (Fig. 2G) and $\mu$-XRF (Fig. 2H). In both cases, very high concentrations of $\mathrm{Cd}$ were observed in the endodermis, followed by the stele, epidermis, and cortex. Similar to the imaging analysis, the semi-quantitative concentrations of Cd, generated using SEM-WDS, were higher (5-fold) in the endodermis (Fig. 3C) and there were no differences between staining of the apoplast and symplast in the cortex (Fig. 3D).

\subsection{Estimated speciation of $\mathrm{Cd}$ in the roots}

Representative $\mu$-XANES spectra from different tissues within barley and lettuce roots, as well as the reference compounds, are shown in Figure 4. Each reference compound had a unique spectrum; the spectra of the plant tissues were similar but not identical to one another. Linear combination fitting of the root spectra with the reference spectra was used to estimate the proportion of $\mathrm{Cd}^{2+}$ that was bound to each of the ligands (Table 2). While some of the $\mathrm{Cd}^{2+}$ in both lettuce and barley was coordinated with each of the 
ligands tested, marked differences in the coordination environments were detected among tissues and between the two plant species.

In the cortex and stele of lettuce root, greater than $85 \%$ of the $\mathrm{Cd}^{2+}$ was coordinated with $\mathrm{S}$ or $\mathrm{SO}_{4}$ and the remainder was predicted to be bound to acetate (Table 2). In the epidermis and endodermis of lettuce, $82-84 \%$ of the $\mathrm{Cd}^{2+}$ was fairly evenly distributed among $\mathrm{Cl}_{2}, \mathrm{NO}_{3}$ and $\mathrm{O}$ ligands, with the remainder predicted to be $\mathrm{CdS}$.

In the epidermis, endodermis and stele of barley root, greater than $76 \%$ of the $\mathrm{Cd}^{2+}$ was coordinated with $\mathrm{S}$ or $\mathrm{SO}_{4}$ and the remainder was estimated to be bound to acetate (Table 2). The pattern was different in the cortex of barley root, where $83 \%$ of the Cd was evenly distributed among $\mathrm{S}, \mathrm{Cl}_{2}$ and $\mathrm{O}$ ligands and less than $10 \%$ was bound to each of $\mathrm{SO}_{4}$ and $\mathrm{NO}_{3}$.

\section{Discussion}

Exposure to 5 or $10 \mathrm{mM} \mathrm{CdCl}_{2}$, even for a period as short as $1 \mathrm{~h}$, is an extreme condition that is not representative of natural or agricultural conditions, and it is recognized that the resulting distributions of $\mathrm{Cd}$ in lettuce and barley are not indicative of particular physiological responses within these plants. While these concentrations were necessary to determine the distribution of $\mathrm{Cd}$ among the various tissue types and compartments within the roots, it is apparent that Cd did not simply flood into the roots and overwhelm the available ligands. Not only was very little of the total Cd in the roots estimated to be $\mathrm{CdCl}_{2}$, but we observed marked differences in the distribution and coordination 
environments of Cd in lettuce as compared to barley. Thus, the results of our analyses are indicative of the chemical interactions between Cd and various cellular components.

\subsection{Distribution of Cd between roots and shoots}

The two plant species differed in their ability to tolerate acute exposure to Cd. Although barley was exposed to a 2-fold higher concentration of Cd compared to lettuce in the hour prior to harvest, the barley appeared healthy whereas lettuce was visibly wilted. This may have been the result of lettuce having 4-fold higher concentrations of $\mathrm{Cd}$ in the shoots, and about $25 \%$ higher concentrations of Cd in the roots, as compared to barley. Although $1 \mathrm{~h}$ was not enough time for all of the available $\mathrm{Cd}$ to be translocated from the roots to the shoot, it is apparent that $\mathrm{Cd}$ more easily enters lettuce roots than barley roots and the proportion of Cd translocated to the shoots of lettuce was higher than that of barley. This is consistent with a previous study (Akhter et al. 2012) in which, after lettuce and barley were grown for 28 days in nutrient solution containing $1 \mu \mathrm{M} \mathrm{CdCl}_{2}$, a 4-fold higher proportion of the Cd taken up was retained in the root of barley compared to the root of lettuce. The question remains: what prevents more Cd from being taken up and translocated to the shoots in barley?

\subsection{Localization and chemical speciation of $\mathrm{Cd}$ in the root}

After comparing the intensity of Cd signals in different tissues in lettuce and barley, we propose that the difference in translocation of $\mathrm{Cd}$ to the shoot in these two species depends on their ability to immobilize Cd in the root. The biggest differences between barley and lettuce appear to be increased binding of $\mathrm{Cd}$ in the endodermis and xylem cell 
walls in barley and decreased sequestration of $\mathrm{Cd}$ in the symplast (probably in the vacuoles) of cortical cells in lettuce.

The coordination environments of Cd, as estimated by $\mu$-XANES, provide additional information about the formation of Cd-complexes in the roots. The presence of $\mathrm{CdCl}_{2}$ is most likely due to residual $\mathrm{CdCl}_{2}$ from the $1 \mathrm{~h}$ pre-harvest incubation. It is not clear why $\mathrm{CdCl}_{2}$ was not detected in epidermal cells of barley and cortical cells of lettuce. The chemicals selected as reference compounds are representative of ligands that can be expected to form complexes with $\mathrm{Cd}^{2+}$, which are discussed below.

The plant cell wall consists of polysaccharides, including cellulose and hemicellulose, as well as pectin and proteins. In our experiment, binding of $\mathrm{Cd}^{2+}$ to the cell wall would be detected through $\mathrm{Cd}-\mathrm{O}, \mathrm{Cd}-\mathrm{NO}_{3}$ and $\mathrm{Cd}$-acetate coordination environments, which are representative of binding to hydroxyl, amino and carboxyl groups, respectively. de la Rosa et al. (2004) also interpreted Cd-O signals as being indicative of binding to the cell wall. While Cd-acetate is not expected in plant roots, its carboxyl group provides a coordination environment similar to that of carboxylic acids such as citrate and malate that are known to bind metals in plants (Krotz et al., 1989), as well as to pectins in the cell wall. In a study by Diacomanolis et al. (2010), XANES spectra for Cd-S and Cdmetallothionein (a cysteine-rich protein that forms complexes with Cd in the same manner as phytochelatin) were almost indistinguishable. In our study, the presence of Cd-S bonds suggests the chelation of $\mathrm{Cd}^{2+}$ with molecules that contain thiol groups, such as phytochelatins (de la Rosa et al., 2004), or binding with acid-labile sulphur, either of 
which would reflect accumulation of Cd in vacuoles (reviewed in Sanità di Toppi and Gabbrielli, 1999).

Closer examination of the distribution of $\mathrm{Cd}$ among root tissues and the estimated speciation of Cd within each tissue provides additional information about differential transport of Cd in barley as compared to lettuce.

\subsubsection{Epidermis}

The epidermis provided the first barrier to $\mathrm{Cd}^{2+}$ uptake in both species and, as a result, $\mathrm{Cd}$ accumulated in this region. Others have also reported a high concentration of $\mathrm{Cd}$ in the epidermis (Küpper et al., 2000; Van Belleghem et al., 2007; Hu et al., 2009). In lettuce, most $\mathrm{Cd}^{2+}$ in the epidermis was predicted to be coordinated with $\mathrm{NO}_{3}$ and $\mathrm{O}$, which suggests binding to the cell walls.

In barley, most of the $\mathrm{Cd}^{2+}$ in the epidermis was predicted to be bound to ligands that contained $\mathrm{SO}_{4}$ or acetate. This can be interpreted as binding of $\mathrm{Cd}$ with phytochelatins in the symplasm and to pectins in the cell wall, respectively. We did not investigate whether $\mathrm{Cd}$ in the epidermis was in the apoplast or symplast; to do so would require a spectroscopic technique with resolution to the nanometer scale.

Küpper et al. (2000) studied the distribution of Cd in the roots of hydroponically grown Arabidopsis halleri and found cadmium phosphate $\left(\mathrm{Cd}_{3}\left(\mathrm{PO}_{4}\right)_{2}\right)$ precipitates in the epidermis. We did not include $\mathrm{Cd}_{3}(\mathrm{PO} 4)_{2}$ in our set of reference materials because we were unable to find a commercial source of that compound; however, we expect that similar precipitates would have been in the epidermis of our plants. 
Between the epidermis and cortex, barley has an additional layer of cells called the exodermis (Gierth et al., 1999), which has a Casparian strip consisting of pectin and suberin that can block the radial flow of water, nutrients and other ions (Gierth et al., 1999). The high concentration of Cd observed between the epidermis and cortex in barley roots is likely due to accumulation of $\mathrm{Cd}$ in the exodermis.

\subsubsection{Cortex}

The concentration of Cd was lower in the cortex in both lettuce and barley compared to other tissues in the root; however, the largest proportion of root volume is made up of the cortex and it probably plays an important role in retaining $\mathrm{Cd}$ in the root. The images from Cd-dithizone stain, SEM-WDS and $\mu-\mathrm{XRF}$, as well as the semi-quantitative analysis using SEM-WDS, showed that the species differed in the distribution of Cd in the cortex. In lettuce, 5 times more Cd was estimated to be in the apoplast compared to the symplast, whereas Cd was evenly distributed between the apoplast and symplast in barley. This result was consistent with Akhter et al. (2012), in which lettuce and barley were exposed to $5.0 \mathrm{mM} \mathrm{Cd}$ for $1 \mathrm{~h}$ followed by desorption of apoplastic $\mathrm{Cd}^{2+}$ using $\mathrm{CaCl}_{2}$.

The $\mu$-XANES data for lettuce do not support the predominance of apoplastic Cd in the cortex because only $15 \%$ of the Cd was estimated to be bound to carboxylic ligands (acetate) and none was predicted to be bound to $\mathrm{O}$ or $\mathrm{NO}_{3}$-ligands. With $85 \%$ of the $\mathrm{Cd}^{2+}$ being coordinated with S-ligands, one might conclude that Cd-phytochelatin complexes formed in lettuce symplast but this is neither supported by Akhter et al. (2012), who did not detect any phytochelatins in the roots of lettuce, nor by our SEM-WDS data. The Cd$\mathrm{S} / \mathrm{SO}_{4}$ signal likely represents binding to metallothionenes or other S-rich proteins. The 
$\mu$-XANES data for barley is consistent with the other measurements, with equal proportions of $\mathrm{Cd}$ forming complexes in the apoplast (with $\mathrm{NO}_{3}$ and $\mathrm{O}$ ) and the symplast (with $\mathrm{S}$ and $\mathrm{SO}_{4}$ ). Between apoplastic and symplastic Cd, apoplastic Cd is more available for translocation to the shoot. Symplastic Cd is more immobile since the $\mathrm{Cd}^{2+}$ ions form complexes with chelators that accumulate in the vacuole. Symplastic Cd has been reported in the roots of a number of species including Arabidopsis thaliana (Van Belleghem et al., 2007) and Echinochloa polystachyas (Solís-Domínguez et al., 2007). Salt et al. (1995) exposed Brassica juncea seedlings to $0.6 \mu \mathrm{g} / \mathrm{mL} \mathrm{Cd}$ for $7 \mathrm{~d}$ and found that majority of the $\mathrm{Cd}^{2+}$ was bound to $\mathrm{S}$ ligands with a probable coordination of $\mathrm{Cd}-\mathrm{S}_{4}$. It is not possible to determine the subcellular distribution of $\mathrm{Cd}$ in their study because they analysed bulk root samples.

\subsubsection{Endodermis}

The concentration of Cd was very high in the endodermis compared to other tissues in barley root. Restricted movement of ions from the cortex into the stele is expected due to the presence of the Casparian strip, which blocks the apoplastic movement of ions including $\mathrm{Cd}^{2+}$ (Tester and Leigh, 2001). The only pathway into the stele is via the symplast of the endodermis. A number of other studies also reported a high concentration of Cd in the endodermis (Wojcik et al., 2005; Van Belleghem et al., 2007; Terada et al., 2010).

It was surprising to find no accumulation of $\mathrm{Cd}$ at the endodermis in lettuce root. Either the Casaparian band of lettuce was more permeable to Cd than that of barley, or proportionately more Cd was transported via the symplast of the endodermis to the stele 
in lettuce. This idea is consistent with Yamaguchi et al. (2011), who studied root-to-shoot translocation of Cd in two species of Solanum that differed in their ability to translocate Cd to the shoot. The high Cd translocating species accumulated a lower amount of Cd in the endodermis and was better able to load Cd to the xylem.

\subsubsection{Stele}

Once Cd reaches the stele, it can reenter the apoplast before loading to the xylem vessels (Isaure et al., 2006; Van Belleghem et al., 2007; Hu et al., 2009). This was observed in our study; high Cd signals were detected in the cell walls of xylem vessels in barley. The $\mu$-XANES analysis showed that most of the $\mathrm{Cd}^{2+}$ in the stele of barley was coordinated with S and acetate ligands, which could indicate complexation of Cd with phytochelatins and carboxylic acids in the vacuole, as well as binding to the cell walls. In lettuce, most of the $\mathrm{Cd}^{2+}$ was coordinated with $\mathrm{S}$, indicating symplastic binding.

The ability to load $\mathrm{Cd}^{2+}$ from the xylem parenchyma to the xylem vessels depends on the activity of transporters (Mori et al., 2009). Yamaguchi et al. (2011) suggested that differences in Cd uptake in to the xylem in cultivars of Solanum torvum were due to difference in membrane transporters. Lettuce might have more efficient $\mathrm{Cd}^{2+}$ transporters as compared to barley.

The phloem of barley also contained Cd, which may have been redistributed from the shoot to the root as part of the Cd detoxification process. Phloem-mediated Cd redistribution has been reported in A. thaliana (Van Belleghem et al., 2007) and Triticum aestivum (Cakmak et al., 2000). Mendoza-Cózatl et al. (2008) identified high 
concentrations of phytochelatins, glutathione and Cd in the phloem sap of Brassica napus and suggested that, along with the xylem, the phloem is a conduit for long-distance source-to-sink transport of Cd-phytochelatin and Cd-glutathione complexes. This could be the case in our study because $\mathrm{Cd}^{2+}$ was coordinated with $\mathrm{S}$ ligands in the stele. However, further investigation in which $\mu$-XANES spectra would be collected from the phloem tissues is required. Since lettuce has fewer phytochelatins in the shoot compared to barley (Akhter et al., 2012), one would expect less Cd to be redistributed in lettuce compared to barley.

\subsection{Conclusions}

Our results clearly indicated that the radial movement of Cd across the root was blocked by more effective barriers in barley compared to lettuce. A major barrier appears to be related to cells that have a Casparian band, but it is also possible that $\mathrm{Cd}^{2+}$ is more readily transported across membranes in lettuce. Moreover, a higher concentration of Cd was detected in the symplast of barley, which indicates that barley immobilizes more Cd via chelation in the root compared to lettuce, which would therefore reduce transfer to the shoot. Regardless of the tissue types, most of the $\mathrm{Cd}^{2+}$ formed coordination bonds with $\mathrm{S}$ and $\mathrm{SO}_{4}$ ligands in the roots of barley and with $\mathrm{S}, \mathrm{NO}_{3}$ and $\mathrm{O}$ ligands in the roots of lettuce.

\section{Acknowledgements}

Funding was provided by the Natural Science and Engineering Research Council (NSERC) of Canada Discovery Grant Program (SMM and DM). Use of the Advanced 
Photon Source was supported by the U. S. Department of Energy, Office of Science, Office of Basic Energy Sciences, under Contract No. DE-AC02-06CH11357. PNC/XSD facilities at the Advanced Photon Source, and research at these facilities, are supported by the US Department of Energy - Basic Energy Sciences, a Major Resources Support grant from NSERC, the University of Washington, the Canadian Light Source and the Advanced Photon Source. We thank Mr. Ivan Barker for technical assistance with SEMWDS; Drs. R. Gregory Thorn, Melanie Columbus, Jeremiah Shuster and Gordon Southam for assistance with processing samples, and Dr. William Hendershot for providing the barley seeds.

\section{References}

Ager, F.J., Ynsa, M.D., Dominguez-Solis, J.R., Gotor, C., Respaldiza, M.A., Romero, L.C., 2002. Cadmium localization and quantification in the plant Arabidopsis thaliana using micro-PIXE. Nucl. Instrum. Methods 189, 494-498. doi.org/10.1016/S0168-583X(01)01130-2

Ager, F.J., Ynsa, M.D., Dominguez-Solis, J.R., Lopez-Martin, M.C., Gotor, C., Romero, L.C., 2003. Nuclear micro-probe analysis of Arabidopsis thaliana leaves. Nucl. Instrum. Methods 210, 401-406. doi.org/10.1016/S0168-583X(03)01046-2

Akhter, M.F., Macfie, S.M., 2012. Species-specific relationship between transpiration and cadmium translocation in lettuce, barley and radish. J. Plant Stud. 1, 2-13. doi: 10.5539/jps.v1n1p2 
Akhter, M.F., McGarvey, B., Macfie, S.M., 2012. Reduced translocation of cadmium from roots is associated with increased production of phytochelatins and their precursors. J. Plant Physiol. 169, 1821-1829. doi.org/10.1016/j.jplph.2012.07.011

Bert, V., Bonnin, I., Saumitou-Laprade, P., de Laguérie, P., Petit, D., 2002. Do Arabidopsis halleri from nonmetallicolous populations accumulate zinc and cadmium more effectively than those from metallicolous populations? New Phytol. 155, 47-57. doi: 10.1046/j.1469-8137.2002.00432.x

Cakmak I., Welch, R.M., Hart, J., Norvell, W.A., Oztu, L., Kochian, L.V., 2000. Uptake and retranslocation of leaf-applied cadmium $\left({ }^{109} \mathrm{Cd}\right)$ in diploid, tetraploid and hexaploid wheats. J. Exp. Bot. 51, 221-226. doi: 0.1093/jexbot/51.343.221

Cocozza, C., Minnocci, A., Tognetti, R., Lori, V., Zacchini, M., Scarascia Mugnozza, G., 2008. Distribution and concentration of cadmium in root tissue of Populus alba determined by scanning electron microscopy and energy-dispersive X-ray microanalysis. iForest 1, 96-103. doi: 10.3832/ifor0458-0010096

Cosio, C., Vollenweider, P., Keller, C., 2006. Localization and effects of cadmium in leaves of a cadmium-tolerant willow (Salix viminalis L.) I. Macrolocalization and phytotoxic effects of cadmium. Environ. Exp. Bot. 58, 64-74. doi.org/10.1016/j.envexpbot.2005.06.017

de la Rosa, G., Peralta-Videa, J.R., Montes, M., Parson, J.G., Cano-Aguilera, I., GardeaTorresdey, J.L., 2004. Cadmium uptake and translocation in tumbleweed (Salsola kali), a potential Cd-hyperaccumulator desert plant species: ICP/OES and XAS studies. Chemosphere 55, 1159-1168. doi: 10.1016/j.chemosphere.2004.01.028 
Diacomanolis, V., Ng, J.C., Sadler, R., Harris, H.H., Nomura, M., Noller, B.N., 2010.

Direct examination of cadmium bonding in rat tissues dosed with mine wastes and cadmium-containing solutions. AIP Conf Proc 1234, 613-616. doi: 10.1063/1.3463281.

Fukuda, N., Hokura, A., Kitajima, N., Terada, Y., Saito, H., Abe, T., Nakai, I., 2008. Micro X-ray fluorescence imaging and micro X-ray absorption spectroscopy of cadmium hyper-accumulating plant, Arabidopsis halleri ssp. gemmifera, using highenergy synchrotron radiation. J. Anal. Atom. Spectrom. 23, 1068-1075. doi: 10.1039/B803602K

Gierth, M., Stelzer, R., Lehmann, H. 1999. An analytical microscopical study on the role of exodermis in apoplastic $\mathrm{Rb}^{+}\left(\mathrm{K}^{+}\right)$transport in barley roots. Plant Soil 207, 209218. doi: 10.1023/A:1004437516331

Goldstein, J.I., Newbury, D.E., Echlin, P., Joy, D.C., Romig, Jr., A.D. , Lyman, C.E., Fiori, C. and Lifshin, E. 1992. Scanning Electron Microscopy and X-ray Microanalysis Plenum Press, New York.

Harada, E., Hokura, A., Takada, S., Baba, K., Terada, Y., Nakai, I., Yazaki, K., 2010. Characterization of cadmium accumulation in willow as a woody metal accumulator using synchrotron radiation-based X-ray microanalyses. Plant Cell Physiol. 51, 848853. doi: $10.1093 /$ pcp/pcq039

Hu, P-J., Qiu, R-L., Senthilkumar, P., Jiang, D., Chen, Z-W., Tang, Y-T., Liu, F-J., 2009. Tolerance, accumulation and distribution of zinc and cadmium in hyperaccumulator Potentilla griffithii. Environ. Exp. Bot., 66, 317-325.

doi.org/10.1016/j.envexpbot.2009.02.014 
Isaure, M-P., Fayard, B., Sarret, G., Pairis, S., Bourguignon, J., 2006. Localization and chemical forms of cadmium in plant samples by combining analytical electron microscopy and X-ray spectromicroscopy. Spectrochim. Acta B, 61, 1242-1252. doi.org/10.1016/j.sab.2006.10.009

Krotz, R.M., Evangelou, B.P., Wagner, G.J.,1989. Relationships between cadmium, zinc, Cd-peptide and organic acid in tobacco suspension cells. Plant Physiol. 91, 780-787. doi.org/10.1104/pp.91.2.780

Küpper, H., Lombi, E., Zhao, F-J., Mcgrath, S.P., 2000. Cellular compartmentation of cadmium and zinc in relation to other elements in the hyperaccumulator Arabidopsis halleri. Planta 211, 75-84. doi: 10.1007/s004250000366

Liu, D., Kottke, I., 2004. Subcellular localization of cadmium in the root cells of Allium cepa by electron energy loss spectroscopy and cytochemistry. J. Biosci. 29, 329-335. doi: 10.1007/BF02702615

Lozano-Rodriguez, E., Hernandez, L.E., Bonay, P., Carpena-Ruiz, R.O., 1997.

Distribution of cadmium in shoot and root tissues of maize and pea plants:

Physiological disturbances. J. Exp. Bot. 48, 123-128. doi: 10.1093/jxb/48.1.123

Mendoza-Cózatl, D.G., Butko, E., Springer, F., Torpey, J.W., Komives, E.A., Kehr, J., Schroeder, J.I., 2008. Identification of high levels of phytochelatins, glutathione and cadmium in the phloem sap of Brassica napus. A role for thiol-peptides in the longdistance transport of cadmium and the effect of cadmium on iron translocation. Plant J. 54, 249-259. doi: 10.1111/j.1365-313X.2008.03410.x 
Migeon, A., Audinot, J-N., Eybe, T., Richaud, P., Damien, B., Migeon, H-N., Chalot, M., 2011. Cadmium and zinc localization by SIMS in leaves of Populus deltoides (cv. Lena) grown in a metal polluted soil. Surf. Anal., 43, 367-369. doi: 10.1002/sia.3445

Mori, S., Uraguchi, S., Ishikawa, S., Arao, T., 2009. Xylem loading process is a critical factor in determining $\mathrm{Cd}$ accumulation in the shoots of Solanum melongena and Solanum torvum. Environ. Exp. Bot. 67, 127-132. doi.org/10.1016/j.envexpbot.2009.05.006

Naftel, S.J., Martin, R.R., Macfie, S.M., Courchesne, F., Séguin, V., 2007. An investigation of metals at the soil/root interface using synchrotron radiation analysis. Can. J. Anal. Sci. Spect. 52, 18-24.

Ouariti, O., Gouia, H., Ghorbal, M.H., 1997. Responses of bean and tomato plants to cadmium: Growth, mineral nutrition and nitrate reduction. Plant Physiol. Biochem. 35, 347-354.

Pielichowska, M., Wierzbicka, M., 2004. Uptake and localization of cadmium by Biscutella laevigata, a cadmium hyperaccumulator. Acta Biol. Cracov. Bot. 46, 5763.

Rauser, W.E., Ackerley, C.A., 1987. Localization of cadmium in granules within differentiating and mature root cells. Can. J. Bot. 65, 643-646. doi: 10.1139/b87-084

Salt, D.E., Prince, R.C., Pickering, I.J., Raskin, I., 1995. Mechanisms of cadmium mobility and accumulation in indian mustard. Plant Physiol. 109, 1427-1433. doi: org/10.1104/pp.109.4.1427

Sanità di Toppi L., Gabbrielli R., 1999. Response to cadmium in higher plants. Environ. Exp. Bot. 41, 105-130. doi: org/10.1016/S0098-8472(98)00058-6 
Seregin, I.V., Ivanov, V.B., 1997. Histochemical investigation of cadmium and lead distribution in plants. Russ. J. Plant Physiol.(Engl. Transl.) 44, 791-796.

Solís-Domínguez, F.A., Gonzalez-Chavez, M.C., Carrillo-Gonzalez, R., RodriguezVazquez, R., 2007. Accumulation and localization of cadmium in Echinochloa polystachya grown within a hydroponic system. J. Hazard Mater. 141, 630-636. doi: org/10.1016/j.jhazmat.2006.07.014

Terada, Y., Abe, T., Nakai, I., 2010. Study on accumulation mechanism of cadmium in rice (Oriza sativa L.) by micro-XRF imaging and X-ray absorption fine structure analysis utilizing synchrotron radiation. Bunseki Kagaku 59, 463-475. doi: 10.2116/bunsekikagaku.59.463

Tester, M., Leigh, R.A., 2001. Partitioning of nutrient transport processes in roots. J. Exp. Bot. 52, 445-457. doi: 10.1093/jexbot/52.suppl_1.445

Van Belleghem, F.V., Cuypers, A., Semane, B., Smeets, K., Vangronsveld, J., d’Haen, J., Valcke, R., 2007. Subcellular localization of cadmium in roots and leaves of Arabidopsis thaliana. New Phytol. 173, 495-508. doi: 10.1111/j.14698137.2006.01940.x

Vázquez, M.D., Poschenrieder, C., Barcelo, J., 1992. Ultrastructural effects and localization of low cadmium concentrations in bean roots. New Phytol. 120, 215226.

Vázquez, S., Fernandez-Pascual, M., Sanchez-Pardo, B., Carpena, R.O., Zornoza, P., 2007. Subcellular compartmentalisation of cadmium in white lupins determined by energy-dispersive X-ray microanalysis. J. Plant Physiol. 164, 1235-1238. doi: org/10.1016/j.jplph.2006.11.011 
Vieira da Cunha, K.P., Araujo do Nascimento, C.W., de Mendonca Pimentel, R.M., Ferreira, C.P., 2008. Cellular localization of cadmium and structural changes in maize plants grown on a cadmium contaminated soil with and without liming. J. Hazard Mater. 160, 228-234. doi: org/10.1016/j.jhazmat.2008.02.118

Vogel-Mikuš, K., Simčič, J., Pelicon, P., Budnar, M., Kump, P., Nečemer, M., MesjaszPrzybylowicz, J., Przybylowicz, W., Regvar, M., 2008. Comparison of essential and non-essential element distribution in leaves of the $\mathrm{Cd} / \mathrm{Zn}$ hyperaccumulator Thlaspi praecox as revealed by micro-PIXE. Plant Cell Environ. 31, 1484-1496. doi: 10.1111/j.1365-3040.2008.01858.x

Vollenweider, P., Cosio C., Gunthardt-Goerg, M.S., Keller, C., 2006. Localization and effects of cadmium in leaves of a cadmium-tolerant willow (Salix viminalis L .). Part II Microlocalization and cellular effects of cadmium. Environ. Exp. Bot. 58, 25-40. doi: org/10.1016/j.envexpbot.2005.06.012

Wang, X., Liu, Y., Zeng, G., Chai, L., Song, X., Min Z., Xiao, X., 2008. Subcellular distribution and chemical forms of cadmium in Bechmeria nivea (L.) Gaud. Environ. Exp. Bot. 62, 389-395. doi: org/10.1016/j.envexpbot.2007.10.014

Weigel, H.J., Jäger, H.J., 1980. Subcellular distribution and chemical form of cadmium in bean plants. Plant Physiol. 65, 480-482. doi: org/10.1104/pp.65.3.480

Wu, F-B., Dong, J., Qian, Q.Q., Zhang, G-P., 2005. Subcellular distribution and chemical form of $\mathrm{Cd}$ and $\mathrm{Cd}-\mathrm{Zn}$ interaction in different barley genotypes. Chemosphere 60, 1437-1446. doi: org/10.1016/j.chemosphere.2005.01.071 
Wójcik, M., Vangronsveld, J., d’Haen, J., Tukiendorf, A., 2005. Cadmium tolerance in Thlaspi caerulescens II . Localization of cadmium in Thlaspi caerulescens. Environ. Exp. Bot. 53, 163-171. doi: org/10.1016/j.envexpbot.2004.03.011

Yamaguchi, N., Mori, S., Baba, K., Kaburagi-Yada, S., Arao, T., Kitajima, N., Hokura, A., Terada, Y., 2011. Cadmium distribution in the root tissues of solanaceous plants with contrasting root-to-shoot Cd translocation efficiencies. Environ. Exp. Bot. 71, 198-206. doi: org/10.1016/j.envexpbot.2010.12.002 
Table 1: Concentration and amount of $\mathrm{Cd}$ in lettuce and barley grown in different $\mathrm{CdCl}_{2}$ treatments ${ }^{\mathrm{a}}$ Values are mean (SE), $\mathrm{n}=3$.

\begin{tabular}{cccccc}
\hline Species & $\begin{array}{c}\text { Treatment } \\
\left(\mathrm{mM} \mathrm{CdCl}_{2}\right)\end{array}$ & $\begin{array}{c}\text { Root Cd }^{\mathrm{b}} \\
(\mathrm{mg} / \mathrm{g})\end{array}$ & $\begin{array}{c}\text { Shoot Cd } \\
(\mathrm{mg} / \mathrm{g})\end{array}$ & $\begin{array}{c}\text { Root Cd } \\
(\mathrm{mg})\end{array}$ & $\begin{array}{c}\text { Shoot Cd } \\
(\mathrm{mg})\end{array}$ \\
\hline Lettuce & 5 & $<\mathrm{dl}^{\mathrm{C} * * *}$ & $<\mathrm{dl} * * *$ & $<\mathrm{dl} * * *$ & $<\mathrm{dl} * * *$ \\
\hline Barley & $19.16(0.05)$ & $0.26(0.01)$ & $3.74(0.30)$ & $0.25(0.02)$ \\
\hline
\end{tabular}

\footnotetext{
${ }^{\mathrm{a}}$ Plants were grown with 0 or $1.0 \mu \mathrm{M} \mathrm{CdCl}_{2}$ for $28 \mathrm{~d}$. The plants grown with Cd were transferred to either $5.0 \mathrm{mM} \mathrm{CdCl}{ }_{2}$ (lettuce) or 10.0 $\mathrm{mM} \mathrm{CdCl} 2$ (barley) for $1 \mathrm{~h}$ immediately prior to harvest.

${ }^{\mathrm{b}}$ Significant differences in Cd concentration and Cd accumulation between control and Cd-treated roots and shoots were determined using t-tests; $* \mathrm{P}<0.05, * * \mathrm{P}<0.01, * * * \mathrm{P}<0.001$. For the purpose of statistical analysis, values below the detection limit were assigned a number equal to $1 / 2$ of the detection limit.

${ }^{\mathrm{c}} \mathrm{dl}=$ detection limit $(=0.001 \mathrm{mg} / \mathrm{g})$.
} 
Table 2: Linear combination fitting of normalized $\mu$-XANES spectra for four tissues in barley and lettuce roots. The standard error of the mean for each of the estimated contributions was $<0.001$.

\begin{tabular}{|c|c|c|c|c|c|c|c|c|}
\hline \multirow[b]{2}{*}{ Species } & \multicolumn{8}{|c|}{$\begin{array}{c}\text { Estimated \% contribution of each ligand to the linear } \\
\text { model of best fit }{ }^{\mathrm{a}}\end{array}$} \\
\hline & Cell type & $\mathrm{CdSO}_{4}$ & $\mathrm{CdS}$ & $\mathrm{CdCl}_{2}$ & $\mathrm{CdNO}_{3}$ & Cd-Acetate & $\mathrm{CdO}$ & R-factor ${ }^{b}$ \\
\hline \multirow{4}{*}{ Lettuce } & Epidermal & - & 14.7 & 26.9 & 29.4 & - & 29.1 & 0.0010 \\
\hline & Cortex & 45.3 & 40.2 & - & - & 14.5 & - & 0.0007 \\
\hline & Endodermal & - & 16.9 & 30.8 & 13.2 & - & 39.1 & 0.0013 \\
\hline & Stele & 64.5 & 28.9 & - & - & 6.6 & - & 0.0060 \\
\hline \multirow{4}{*}{ Barley } & Epidermal & 68.5 & 7.3 & - & - & 24.3 & - & 0.0035 \\
\hline & Cortex & 7.6 & 28.2 & 32.4 & 9.4 & - & 22.4 & 0.0008 \\
\hline & Endodermal & 54.1 & 33.9 & - & - & 12.0 & - & 0.0026 \\
\hline & Stele & 40.9 & 37.0 & - & - & 22.2 & - & 0.0036 \\
\hline
\end{tabular}

${ }^{\mathrm{a}}$ Complexes that were not included in the model of best fit are indicated by -

${ }^{\mathrm{b}} \mathrm{R}$-factor is a measure of the misfit (residuals) between the model and the experimental data 


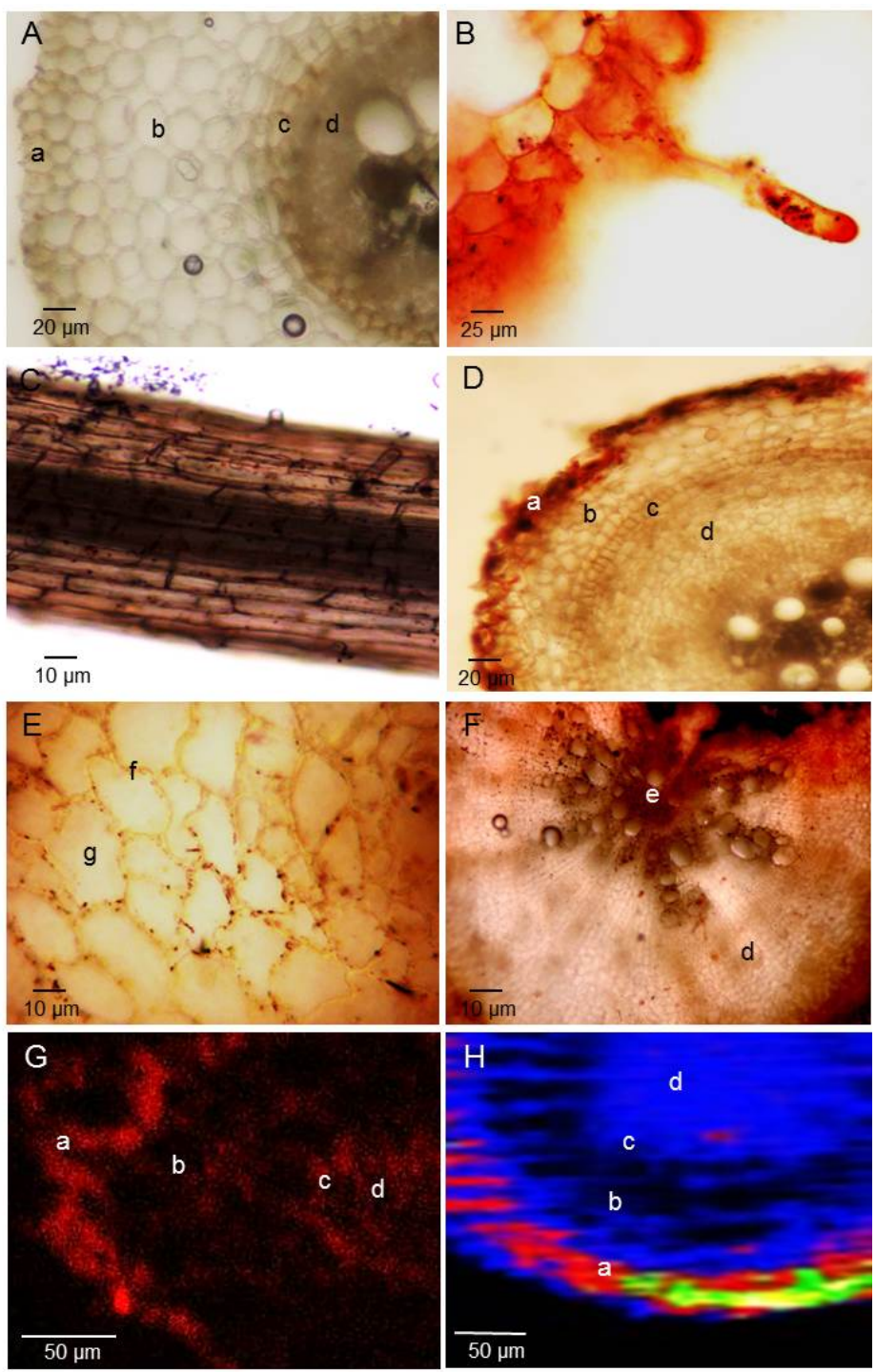

Fig. 1: Localization of Cd in the tissues and cells of lettuce.

Within the figure: (A) root cross section (c.s.), without Cd treatment (control), (B to H) Cd-treated roots, (B) root hair, (C) root surface, (D) root c.s., (E) cortical cells, (F) stele, (G) SEM-WDS Cd map, (H) $\mu$-XRF Cd map. Different tissues in the root are: (a) epidermis, (b) cortex, (c) endodermis, (d) stele, (e) xylem, (f) apoplast and (g) symplast. Red stain (A-F) and red colourization $(G, H)$ indicate high concentrations of Cd; in $(H)$, orange, yellow, green, blue and black indicate progressively lower concentrations of Cd. 


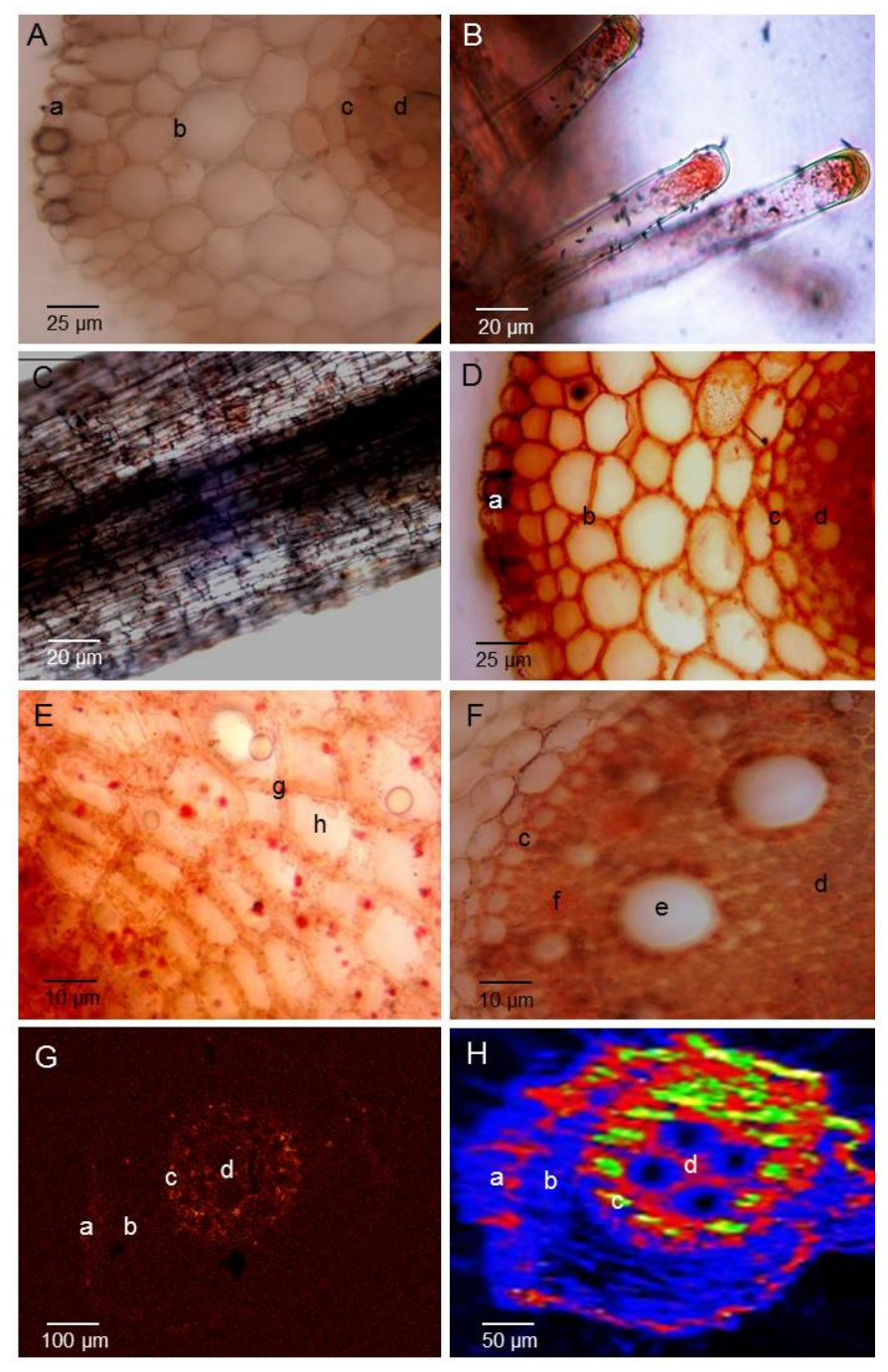

Fig. 2: Localization of Cd in the tissues and cells of barley.

Within the figure: (A) root cross section (c.s.), without Cd treatment (control), (B to H) Cd-treated roots, (B) root hair, (C) root surface, (D) root c.s., (E) cortical cells, (F) stele, (G) SEM-WDS Cd map, (H) $\mu$-XRF Cd map. Different tissues in the root are: (a) epidermis, (b) cortex, (c) endodermis, (d) stele, (e) xylem, (f) apoplast and (g) symplast. Red stain (A-F) and red colourization $(G, H)$ indicate high concentrations of Cd; in $(H)$, orange, yellow, green, blue and black indicate progressively lower concentrations of Cd. 

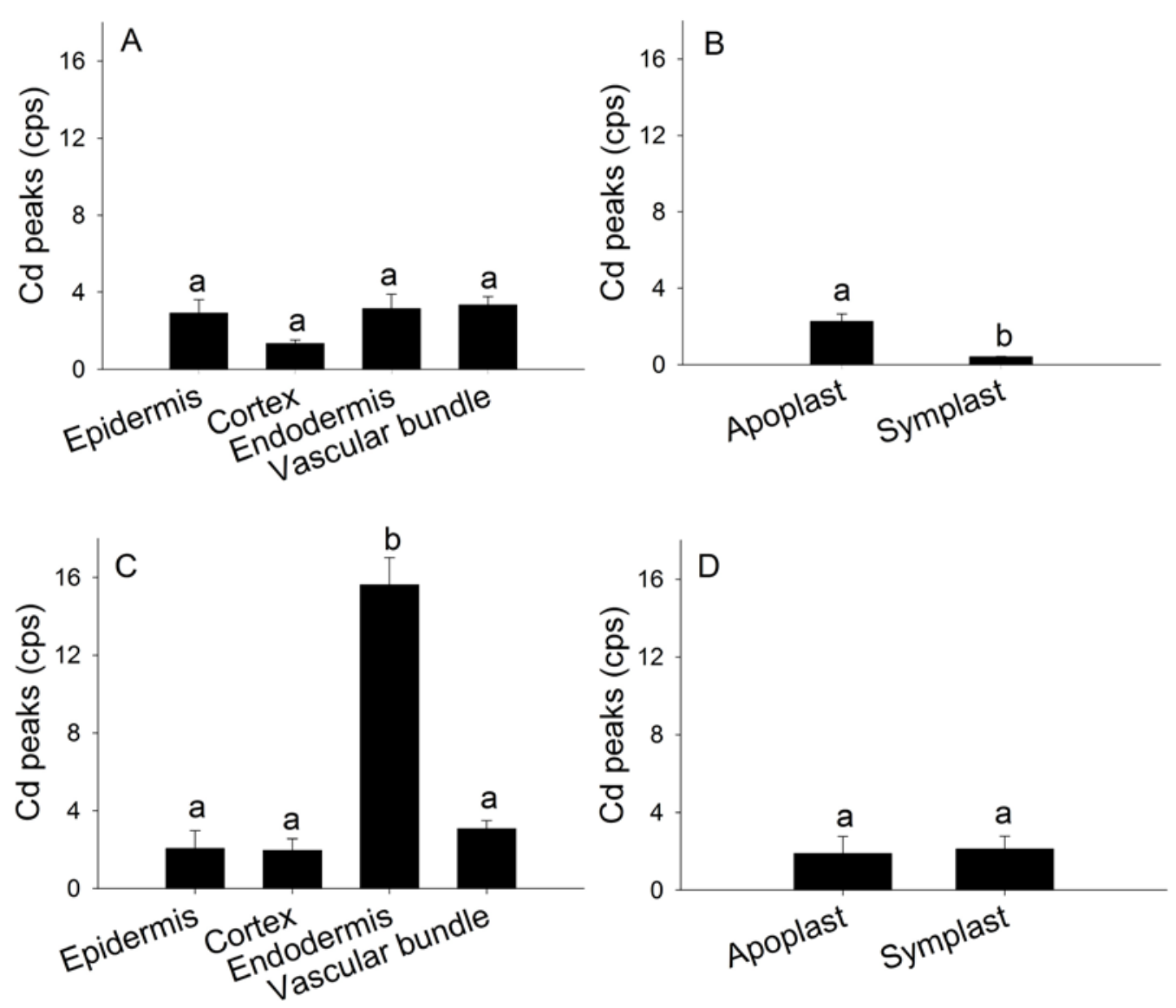

Fig. 3: Relative amount (+SE) of Cd in four tissues and in the apoplast or symplast of cortical cells of Cd-treated roots.

A transect across each of 3 replicate roots was analyzed using SEM-WDS. Within each root, the mean counts per second (cps) from all spots representing each of the tissues and regions was calculated, these values represent the cps signals from that replicate. (A) lettuce root tissues, (B) apoplast and symplast within the cortex of lettuce, (C) barley root tissues, and (D) apoplast and symplastic within the cortex of barley. Within each panel, different lower case letters indicate significant differences in $\mathrm{Cd}$ accumulation, as determined by one-way ANOVA followed by post-hoc Tukey tests. 


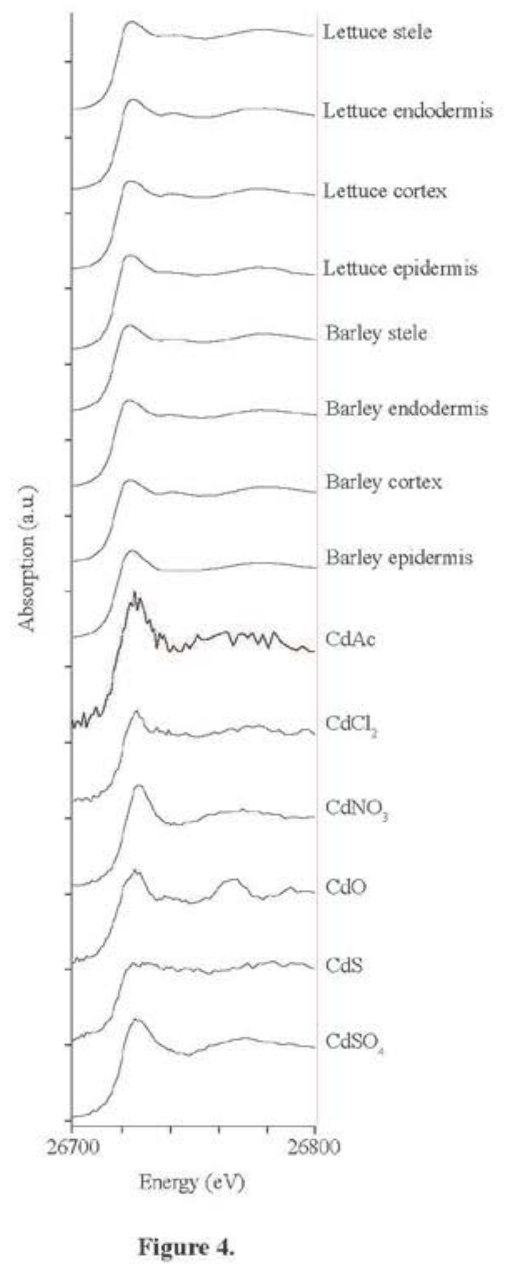

Fig. 4: Cadmium K-edge $\mu$-XANES spectra from four tissues in the roots of lettuce and barley, as well as the six reference compounds. (a) lettuce stele, (b) lettuce endodermis, (c) lettuce cortex, (d) lettuce epidermis, (e) barley stele, (f) barley endodermis, (g) barley cortex, (h) barley epidermis, (i) $\mathrm{CdS}$, (j) $\mathrm{CdCl}_{2}$, (k) $\mathrm{Cd}\left(\mathrm{NO}_{3}\right)_{2}$, (l) $\mathrm{CdO}$, (m) $\mathrm{CdSO}_{4}$, (n) Cd-acetate. 